\title{
Do ideal de robustez ao ideal de magreza: Educação Física, saúde e estética
}

\author{
Maria Isabel Brandão de Souza Mendes*
}

\begin{abstract}
Resumo: Modelos de beleza e saúde se misturam e percorrem uma diversidade de cenários educativos. Diante da associação entre saúde e um padrão específico de estética objetivamos discutir sobre a relação entre Educação Física, saúde e estética. Durante o processo de análise estabelecemos relações com a ideologia do ser saudável, enfatizando o ideal de robustez e o ideal de magreza e identificamos que a Educação Física contribui com a associação entre saúde e um padrão específico de estética corporal por meio de medições antropométricas, quer pelo coeficiente de robustez, quer pelo método para identificar o somatotipo ou pelo índice de massa corporal.

Palavras-chave: Educação Física. Saúde. Estética.
\end{abstract}

\section{INTRODUÇÃo}

O entrelaçamento entre saúde e estética se manifesta através de diferentes discursos e intervenções ao longo da tradição ocidental e revelam rupturas e continuidades. Na contemporaneidade é possível observar em diferentes momentos e lugares a associação entre saúde e um padrão específico de estética corporal.

Se observarmos o anúncio de suplementos nutricionais da empresa "Integralmédica", identificamos a exibição de textos e imagens que dão visibilidade a corpos atléticos campeões. Performance, saúde e beleza são evocados no panfleto de propaganda para chamar a atenção do leitor sobre o objetivo da empresa, como pode ser observado nas seguintes frases:

O objetivo da Integralmédica é promover "Performance, Saúde e Beleza", sempre em busca da compreensão do metabolismo humano e de toda transformação que os nutrientes sofrem no organismo.

"Graduada em Educação Física pela UFRJ. Mestre e Doutora em Educação pela UFRN. Natal, RN, Brasil. E-mail: isabel@cefetrn.br 


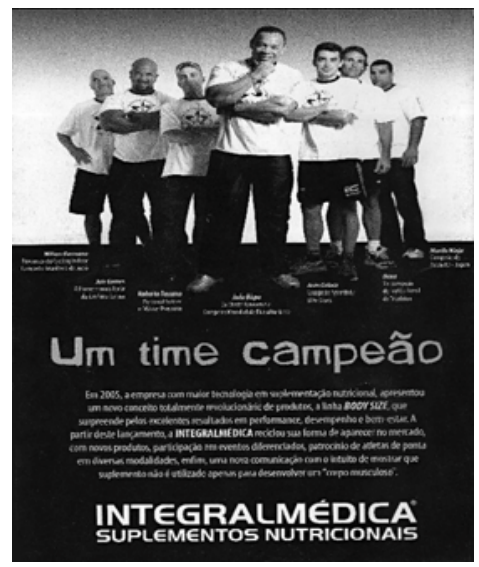

Figura 1. Panfleto

"Em nossos produtos, utilizamos as mais nobres matérias-primas para oferecer a você o que há de melhor na área de Suplementação Nutricional."”

Modelos de beleza e saúde se misturam e percorrem uma diversidade de cenários educativos.

No cenário acadêmico também podemos perceber a associação entre saúde e um padrão específico de estética corporal nos discursos de estudantes do Curso de Graduação em Educação Física. Referimos-nos aqui às discussões da disciplina Filosofia da Educação Física ministrada na Universidade Federal do Rio Grande do Norte. ${ }^{2}$

Diante da problemática apresentada ressaltamos a necessidade de interrogar como a Educação Física contribui para essa associação em diferentes contextos epistemológicos. Nesse sentido, procurando discutir sobre a relação entre Educação Física, saúde e estética, buscamos estabelecer relações com a ideologia do ser saudável, enfatizando o ideal de robustez e o ideal de magreza.

${ }^{1}$ Citação de texto que integra o panfleto sobre suplementos nutricionais de uma fábrica paulista, adquirido em novembro de 2006 em uma das farmácias da cidade de Assu, interior do Rio Grande do Norte, para ser discutido com os alunos do Curso Técnico de Agroecologia da Educação de Jovens e Adultos na Disciplina Educação Física, do CEFET-RN / UNED-Ipanguaçu.

${ }^{2}$ Nos reportamos às discussões realizadas em 2003 no primeiro semestre.

${ }^{3} \mathrm{O}$ corpus de análise foi composto de artigos selecionados a partir das seguintes temáticas: corpo, biologia, atividade física, fisiologia do esforço e saúde.

Movimento, Porto Alegre, v. 15, n. 04, p. 175-191, outubro/dezembro de 2009. 
Para tanto, nos dirigimos primeiramente para estudos que se remetem ao final do século XIX e início do XX, em especial estudos do médico Renato Kehl e do educador Fernando de Azevedo. Nesse contexto, quem produzia conhecimento sobre a prática de exercícios físicos eram os médicos, os militares e pedagogos principalmente, como podemos observar no texto de Bracht (1998).

Posteriormente, nos dirigimos para a Revista Brasileira de Ciências do Esporte (RBCE) digitalizada no período de 1979 a $2003 .{ }^{3}$ A RBCE é uma publicação do Colégio Brasileiro de Ciências do Esporte (CBCE), considerado como principal entidade científica do Brasil que congrega pesquisadores, profissionais e estudantes de diferentes áreas do conhecimento relacionadas à Educação Física e em 2008 comemorou 30 anos de existência.

Com a identificação de que a Educação Física contribui com a associação entre saúde e um padrão específico de estética corporal, por meio de medições antropométricas, destacamos que um dos desafios para os profissionais da Educação Física é reconhecer a diversidade de corpos existentes na sociedade e tematizar os cuidados com o corpo em busca de saúde sem se fixar em um padrão ideal.

\section{Do IDEAL DE ROBUSTEZ AO IDEAL DE MAGREZA}

A Educação Física refere-se a uma prática social que desde a sua origem consiste no ensino de exercícios físicos, jogos e esportes nas instituições escolares, e que era denominada Ginástica científica (SOARES, 2001).

O final do século XIX e o início do XX foram emblemáticos para o reconhecimento da Educação Física brasileira na educação escolar, como ressaltam os trabalhos de Azevedo (1920; 1960), Soares (2001)e Vago (1999).

No final do século XIX e início do XX no Brasil, a Educação Física brasileira se fundamentava nas teorias advindas do universo europeu. Essas teorias davam suporte aos conhecimentos dos médicos brasileiros, buscando contribuir com a construção de um novo homem para o país (SOARES, 2001).

Movimento, Porto Alegre, v. 15, n. 04, p. 175-191, outubro/dezembro de 2009. 


\title{
178 Artigos Orifinais Maria Isabel Brandão de Souza Mendes
}

O povo brasileiro era considerado a caminho da degeneração e da extinção. Além de ser considerado fora dos padrões de civilidade, era reconhecido como doente, sujo, imoral e preguiçoso. A Educação Física, ministrada nas escolas:

\begin{abstract}
contribuiria para forjar o indivíduo forte, robusto, saudável, disciplinado de que tanto carecia a nova sociedade brasileira em formação. [...] A Educação Física no Brasil, em suas primeiras tentativas para compor o universo escolar, surge como promotora da saúde física, da higiene física e mental, da educação moral e da regeneração ou reconstituição das raças (SOARES, 2001, p. 91).
\end{abstract}

Nesse cenário, o conceito de saúde, construído a partir dos preceitos da Medicina moderna e da Biologia é incorporado pela Educação Física. O conceito de saúde é influenciado pela confiança de que os progressos e inventos do final do século XIX iriam curar os males brasileiros e trazer progresso e desenvolvimento para o país.

Nesse cenário, a Educação Física contribuiu com o entrelaçamento do conceito de saúde ao conceito de estética dentro de uma visão reducionista, compreendida como um padrão único de beleza, tendo como modelo o ideal de robustez.

O embelezamento do corpo por meio do exercício físico visava a aquisição de robustez no final do século XIX e início do XX, como pode ser visualizada na "Cartilha de Higiene", elaborada com muitas imagens e uma linguagem clara e incisiva para atingir ao público

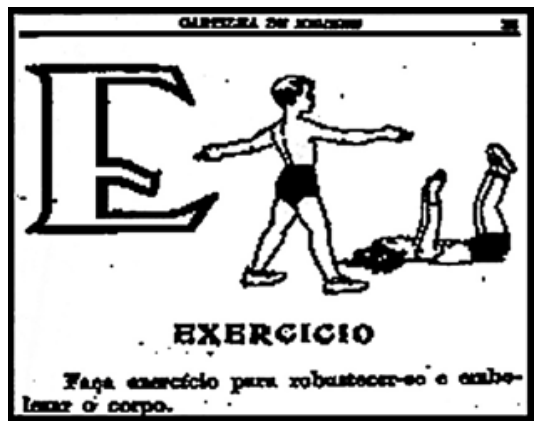

Figura 2. Exercício

Fonte: Kehl, 1936, p. 23.

Movimento, Porto Alegre, v. 15, n. 04, p. 175-191, outubro/dezembro de 2009. 
infantil. Dr. Renato Kehl, escritor da cartilha se dirige aos professores na página introdutória e diz:

Srs. Professores.

Eis, enfim, a prometida "Cartilha de Higiene", que por vezes me foi solicitada, como introdução ao $1^{\circ}$ Livro de Higiene (Fada Hígia), atualmente refundida e em via de $5^{\mathrm{a}}$ edição.

Ofereço-a ao professorado primário como guia para o ensino sugestivo e persuasivo de noções elementares condizentes com a preservação da saúde.

A formação de bons hábitos, como é do consenso pedagógico, deve ser iniciada desde a primeira infância (KEHL, 1936, p. 4).

Em "Fada Hygia", primeiro livro de higiene, Dr. Renato Kehl conta a história da fada da saúde. Uma fada bondosa, bela, amiga e protetora das crianças. "Fada Hygia", a fada da saúde, mora num palácio encantado, de ouro e com belíssimos jardins, onde as crianças se reúnem para escutá-la. A fada da saúde "ensina aos sãos a conservar a vida, a bem vive-la, com prazer e satisfação. Dá conselhos aos doentes para adquirirem de novo a força e a robustez e para não propagarem aos outros os seus males" (KEHL, 1925, p. 2).

No livro "Fada Hygia" existe uma parte em que são apresentados ensinamentos sobre os exercícios físicos, estes relacionados à saúde, beleza e robustez, enquanto a inatividade é associada à doença. Frases curtas e diretas, como as citadas abaixo:

$$
\begin{aligned}
& 2 \text { - A indolência e a preguiça, como a tristeza, são, } \\
& \text { em geral, signaes de doença; } \\
& 3 \text { - Procure ser sempre activo e alegre, trabalhando, } \\
& \text { movendo-se, brincando ou exercitando-se ao ar livre; } \\
& \text { 4-A gymnastica é indispensável á belleza e á robus- } \\
& \text { tez. (KEHL, 1925, p. 85). }
\end{aligned}
$$

A associação entre robustez e saúde também é defendida pelo Dr. Renato Kehl em artigo científico publicado no Brazil-Medico, revista semanal que mantinha relações com a Faculdade de Medicina do Rio de Janeiro e com a Sociedade de Medicina e Cirurgia do Rio de Janeiro. Em 1920 reclama da falta de estudos antropométricos no Brasil que contribuíssem com uma avaliação segura, precisa, pautada

Movimento, Porto Alegre, v. 15, n. 04, p. 175-191, outubro/dezembro de 2009. 
180 Artigos Orifinais Maria Isabel Brandão de Souza Mendes

em medições científicas. Para o referido médico, as avaliações antropométricas poderiam colaborar com o diagnóstico do estado físico das pessoas de diferentes regiões do país e com a verificação do tratamento realizado nos Postos de Saúde (KEHL, 1920).

Para a realização da medição científica, Dr. Renato Kehl apresenta como modelo o índice de robustez de um indivíduo criado pelo Dr. Pignet, médico militar francês e que era utilizado pelo exército da França para excluir os homens considerados como fracos. O coeficiente de robustez de Pignet era adquirido "subtrahindo, dos centimetros de estatura, o numero que representa a somma do peso com os centimetros do perímetro thoraxico" (KEHL, 1920, p. 281).

O coeficiente de robustez proposto pelo Dr. Pignet, contribuía com a elaboração do ideal de saúde a ser difundido pelos médicos. Ao considerar a média mínima como normal, Dr. Renato Kehl reconhecia o povo brasileiro como inferior perante os estrangeiros, tidos como fortes e sadios (KEHL, 1920).

Medir o coeficiente de robustez nas escolas era defendido por Fernando de Azevedo para integrar o Programa de Ginástica pedagógica proposto por ele, em livro revisado em 1960 e que tinha sido escrito em 1920. Para a medição do coeficiente de robustez propõe a inclusão dos exames antropométricos nas escolas, com o objetivo de vigiar o crescimento dos estudantes, saber se o desenvolvimento está acelerado ou muito devagar, mas também para determinar a quantidade e 0 tipo de exercício necessário a ser prescrito (AZEVEDO, 1960).

Sua proposta é de que a mensuração do coeficiente de robustez fosse realizada semestralmente nas escolas. Fernando de Azevedo destaca que "a apreciação da robustez pelo método de Pignet é exata para os adultos" (AZEVEDO, 1960, p. 192). Opta então pelo processo de medição do médico francês, entretanto, com uma ligeira modificação, pois compreende que o desenvolvimento do tórax das crianças e dos adolescentes ainda estava incompleto. Com a ligeira modificação da fórmula de Pignet, o coeficiente de robustez a ser adotado poderia ser adquirido subtraindo-se da estatura, a soma do peso com a circunferência torácica em inspiração e com a circunferência torácica em expiração.

Movimento, Porto Alegre, v. 15, n. 04, p. 175-191, outubro/dezembro de 2009. 
Fernando de Azevedo, defensor da Educação Física nas escolas, propõe ainda a elaboração de cartas sanitárias escolares que incluiriam as informações sobre as avaliações antropométricas. Nestas cartas, os médicos deveriam fornecer dados para a classificação dos alunos, "regulares físicos, isto é, meninos, cujo estado habitual de saúde é bom, e irregulares físicos, aquêles, cujo estado habitual de saúde é sofrível ou mau" (AZEVEDO, 1960, p. 194). Essa classificação também servia para informar quem podia ou não participar das aulas de Educação Física.

Desse modo, percebemos que a Educação Física incorpora nesse período uma compreensão de saúde atrelada ao índice de robustez física. Esse conceito de saúde, assentado a partir de variações quantitativas, é reforçado pela busca de um tipo idealizado de saúde, pelo que é considerado normal. Só que esse normal não é estipulado por variações individuais, mas sim pela relação de uma média estabelecida a partir de mensurações.

O projeto de alcançar o ser saudável ideal propagado na sociedade pelos médicos que tem como intuito instaurar na vida humana a positividade da saúde surge a partir do final do século XVIII, como ressalta Foucault (2001), ao fazer referência à medicina europeia. Numa sociedade em que a procura pelos prazeres da vida era considerada como provocadora de distúrbios na saúde da população e gerava desigualdades sociais, a tarefa do médico tornava-se política. Seu dever era informar, dominar e coagir a população. A vigilância se tornava frequente e pulverizada. A consciência médica se generalizava, difundia-se, e cada indivíduo tinha o dever de obter informações sobre os saberes médicos. Para atingir seus objetivos, então, a medicina moderna não se limitava somente a um conjunto de técnicas da cura e do saber exigidos; abrangia ainda um conhecimento do ser humano saudável, um ser humano modelo, ausente de doença. Com essa postura normativa, não é mais cabível aos médicos unicamente aconselhar sobre a vida em equilíbrio. Estes passam a regular as relações físicas e morais dos indivíduos e da sociedade.

A partir do final do século XVIII, com a instauração da ideologia do ser saudável, o corpo humano é visto de forma fragmentada. $\mathrm{O}$ bio-

Movimento, Porto Alegre, v. 15, n. 04, p. 175-191, outubro/dezembro de 2009. 


\section{Artigor Orifinais Maria Isabel Brandão de Souza Mendes}

poder se instaura e o corpo que vive, suporte do nascimento, da morte, da longevidade e da saúde é controlado para ser inserido no campo produtivo e econômico, servindo, desse modo, para o desenvolvimento da sociedade industrial. As estratégias biopolíticas intentam intervir sobre a maneira de viver, para ampliar a vida, controlar os acidentes, o aleatório, as deficiências. O poder sobre a vida se propõe a instaurar uma administração calculista da existência (FOUCAULT, 1988).

O projeto de alcançar o ser saudável ideal vai se espalhando por diversas épocas e sociedades. No Brasil, do índice de robustez de Pignet ao índice de "magreza" corporal a Educação Física contribuiu com a ressignificação desse projeto e a busca pela boa forma vai sendo sutilmente espalhada pela sociedade através do estilo de vida ativa.

O projeto de alcançar o ser saudável ideal é formado por técnicas e modos de guiar a conduta dos seres humanos. Para Foucault (1997) às técnicas e modos de guiar a conduta dos seres humanos se relacionam com a ideia de governo.

A ideia de governo associada à obediência incondicional aos preceitos médicos, fazem parte das modernas formas de governabilidade, que surgem a partir do processo de secularização das ações e discursos construídos na pastoral cristã. Na pastoral cristã a ideia de governo refere-se a uma espécie de vigilância sobre si atrelada à obediência incondicional ao mestre, ao exame ininterrupto e a confissão exaustiva.

\footnotetext{
A obediência incondicional, o exame ininterrupto e a confissão exaustiva formam, portanto, um conjunto onde cada elemento implica os dois outros; a manifestação verbal da verdade que se esconde no fundo de si mesma aparece como uma peça indispensável ao governo dos homens uma pelos outros, tal como foi realizado nas instituições monásticas e sobretudo cenoobíticas - a partir do século IV. Mas é preciso sublinhar que essa manifestação não tem a finalidade de estabelecer o domínio soberano de si sobre si; o que se espera dela, ao contrário, é a humildade e a mortificação, o distanciamento em relação a si e a constituição de uma relação a si que tende à destruição da forma do si (FOUCAULT, 1997, p. 105).
}

Movimento, Porto Alegre, v. 15, n. 04, p. 175-191, outubro/dezembro de 2009. 
A ideia de governo é discutida por Fraga (2006), que traz reflexões importantes para a Educação Física sobre o governo dos corpos no mercado da vida ativa. Ao ter como foco de estudo o Programa Agita São Paulo, o autor apresenta detalhes sobre a retórica políticosanitária que contribui com a dissimulação de formas de controle.

Diante do debate sobre as artes de governo é interessante também a discussão sobre a vida governada e o governo de si de Fonseca, que nos provoca a estar atentos sobre formas de como não ser governado por esses ditames. Como destaca o autor

essa questão fundamental do 'como não ser governado' seria a contrapartida, a parceira e ao mesmo tempo a adversária das artes de governar. Seria a maneira de desconfiar delas, a maneira de limitá-las, recusá-las, transformá-las (FONSECA, 2008, p. 245).

Retornando aos artigos analisados da RBCE, percebemos que as técnicas e modos de guiar a conduta dos seres humanos se constroem da perseguição do modelo atlético ao peso corporal ideal. A Educação Física pautada na compreensão de que promove saúde e previne doenças, busca combater o sedentarismo e conscientizar a população a praticar exercícios regularmente. Nesse contexto epistemológico, o conceito de saúde é construído predominantemente com base na Medicina do Esporte e se fundamenta principalmente das teorias advindas do universo americano.

A busca passa a ser a de alcançar um baixo teor de gordura através dos modelos de se exercitar e modelos de se alimentar. A atenção é direcionada para o aumento ou a diminuição de peso, decorrentes da relação existente entre o dispêndio de energia e a ingestão de alimentos. O consumo necessário de alimentos é estipulado de acordo com as atividades desenvolvidas, o que nos faz perceber que a dieta e as formas de se exercitar se entrelaçam na busca pela boa forma.

Os alimentos são reconhecidos preferencialmente pela quantidade de calorias, pela capacidade de ser fonte de energia e pela quantidade de gordura. As formas de se exercitar são escolhidas de acordo com o reconhecimento da fonte de energia utilizada para o

Movimento, Porto Alegre, v. 15, n. 04, p. 175-191, outubro/dezembro de 2009. 
184 Artigos Orifinais Maria Isabel Brandão de Souza Mendes

desempenho de cada esporte e são estipuladas de acordo com os testes aplicados nas avaliações funcionais e laboratoriais.

Nesse cenário, são ditados modelos que corroboram com a exacerbação de discursos e intervenções que intentam autorregular os indivíduos e que não têm a preocupação com a percepção individual positiva ou negativa dos elementos do meio.

Desse modo, as prescrições realizadas pelos pesquisadores que publicam artigos na RBCE, apoiadas nos pareceres do American College of Sports Medicine colaboram com a propagação do ideal de alcançar a boa forma, sinônimo de saúde.

Com relação à determinação da gordura corporal, o método de Heath-Carter e que identifica o somatotipo (HEGG et al., 1982; PETROSKI et al., 1982; GUEDES, 1982; DUARTE; PETROSKI, 1983; SOARES et al., 1984) é utilizado até meados da década de 80 do século XX e na década de 90 do referido século emerge o método do Índice de Massa Corporal nas publicações da RBCE (DINOÁ; ASSIS, 1990; OLIVOTO, 1999; SILVA; PETROSKI, 1999; SILVA et al., 1999; PITANGA, 1999; SILVA, 1999; BARA FILHO, 2000; BIESEK et al., 2000; GUEDES; GRONDIN 2002; BANKOFF e MOUTINHO, 2002 e LEITE; NUNES, 2002), contribuindo com a associação da saúde à estética da magreza.

Góis Júnior e Lovisolo (2003), ao falarem sobre as continuidades e cruzamentos do movimento higienista do século $\mathrm{XX}$, ressaltam as semelhanças metodológicas para a identificação dos níveis antropométricos médios dos seres humanos.

No fim do século XX, os higienistas da saúde física muito se utilizaram do método estatístico de Quêtelet, mais especificamente do índice de massa corporal (IMC), para identificar o homem médio e os seus desvios. No XXIV Simpósio Internacional de Ciências do Esporte, dos 12 temas livres apresentados na área de cineantropometria e composição corporal, 10 trabalhos urilizaram-se do método de Quêtelet. Recentemente, uma dissertação de mestrado defendeu a forte influência de Quêtelet na educação física (GÓIS JÚNIOR; LOVISOLO, 2003, p. 46-47).

Movimento, Porto Alegre, v. 15, n. 04, p. 175-191, outubro/dezembro de 2009. 
Esses "novos" parâmetros metodológicos contribuem para que o conceito de saúde, tido como ausência de doença, atrele-se ao conceito reducionista de estética. Essa associação tem sido motivo de discussões nas produções da RBCE, por visar estritamente à aparência através da aquisição de um corpo idealizado pela boa forma, como denuncia o artigo de Anzai (2000); o que já tinha sido problematizado no livro de Yara de Carvalho "O 'mito' da atividade física e saúde", quando a autora discute a relação entre a atividade física e a sociedade de consumo, ressaltando que "esta é uma época 'neurotizada' pela idéia da atividade física como saúde associada à beleza estética como o único caminho para o sucesso, para a felicidade e para o dinheiro" (CARVALHO, 1995, p. 121).

Nesse sentido, a associação da saúde à estética da magreza tem sido reforçada por alguns cenários midiáticos e contribuem com o processo de mercadorização da saúde. Esses discursos propagam um ideal de saúde em vista do consumo de variados produtos, utilizando como chamariz um padrão específico de estética corporal, como denunciam Gonçalves et al. (1995); Gonçalves (1996); Della Fonte e Loureiro (1997); Quint e Matiello Júnior (1999); Anzai (2000); Palma (2001); Melo (2001); Silva (2001) e Góis Júnior e Lovisolo (2003).

Conforme as palavras de Anzai (2000, p. 73):

\begin{abstract}
Se a televisão, a publicidade, o cinema, as revistas, os jornais, e agora a internet, defendem as dietas milagrosas, os músculos torneados e bronzeados, as vitaminas que evitam o envelhecimento, as clínicas de rejuvenescimento e as academias de ginástica, é porque isso tudo dá muito dinheiro. E se muito pouco se fala de afeto e respeito entre as pessoas comuns, não tão lindas e nem tão elegantes como as modelos mas que mesmo assim, se sentem felizes, certamente é porque isso é bem menos rentável.
\end{abstract}

Se voltarmos ao anúncio da Integralmédica e observarmos para além do que está impresso no panfleto, percebemos que os textos e as imagens se complementam. O dito e o não dito interagem e são capazes de comunicar múltiplos significados para os diversos leitores, inclusive a ideia de que o consumo dos suplementos nutricionais se associa 


\section{Artigos Orifinais Maria Isabel Brandão de Souza Mendes}

à exibição de homens musculosos e vitoriosos, considerados "belos" e "saudáveis".

\section{ConsideraçõES FINAIS}

Após a discussão sobre a relação entre Educação Física, saúde e estética em diferentes cenários epistemológicos identificamos a relação com a ideologia do ser saudável atrelada a uma diversidade de discursos. Do ideal de robustez, ao modelo atlético e ao peso corporal ideal, observamos discursos e intervenções alicerçados por uma postura normativa guiada por modelos determinísticos, que expõem guias de conduta que desejam obediência aos preceitos médicos.

Nesse sentido, a Educação Física contribui com a associação entre saúde e um padrão específico de estética corporal por meio de medições científicas. Do coeficiente de robustez, ao método para identificar o somatotipo e ao índice de massa corporal, nos deparamos com medidas antropométricas que contribuem com a classificação das pessoas.

Verificou-se ainda que os cenários midiáticos que contribuem com a mercadorização da saúde ao propagar um ideal de beleza associado ao consumo de vários produtos têm sido problematizados por pesquisadores da Educação Física, como pode ser observado nos artigos analisados da RBCE.

Do que foi destacado nas análises realizadas, enfatizamos a necessidade de levarmos para diferentes cenários educativos essas discussões e não limitarmos à Educação Física a realização de medições antropométricas que contribuem com a classificação das pessoas a partir de uma média considerada "normal" e que ainda contribui com uma lógica excludente.

Desse modo, destacamos que um dos desafios para os profissionais da Educação Física é reconhecer a diversidade de corpos existentes na sociedade e tematizar os cuidados com o corpo em busca de saúde sem se fixar em um padrão ideal. Ressaltamos ainda a importância de buscarmos identificar como os jovens e adultos percebem esse processo de vigilância e controle sobre seus corpos. Abrir espaço em

Movimento, Porto Alegre, v. 15, n. 04, p. 175-191, outubro/dezembro de 2009. 
nossas aulas para identificarmos os significados dados pelos nossos alunos diante de propagandas que exibem corpos considerados "belos" e "saudáveis" associados à venda de algum produto. Refletirmos ainda sobre possibilidades de como não ser governado por esses ditames que nos cercam no dia a dia, sobre as nossas escolhas e resistências.

Movimento, Porto Alegre, v. 15, n. 04, p. 175-191, outubro/dezembro de 2009. 
188 Artigor Origimais Maria Isabel Brandão de Souza Mendes

\begin{abstract}
The ideal of strength to the ideal of thinness: Physical Education, health and aesthetics Abstract: Models of health and beauty come together and offer a variety of scenarios education. Given the association between health and a specific pattern of aesthetic purpose discuss the relationship between physical education, health and aesthetics. During an analysis process we establish relations with the ideology of the healthful being emphasizing the ideal of robustness and the ideal of the thinness and identify that Physical Education contributes with association between health and aesthetic specific standard of corporal by means of anthropometrics measurements, either for the coefficient of robustness, either by the method for identify the somatotip or by index of corporal mass.

Keywords: Physical Education. Health. Aesthetic.
\end{abstract}

El ideal de fuerza al ideal de delgadez: la Educación Física, la salud y la estética

Resumen: Los modelos de salud y belleza se unen y ofrecen una variedad de escenarios de la educación. Dada la asociación entre la salud y un patrón de estética propósito discutir la relación entre la educación física, la salud y la estética. Durante el proceso de la analisis establecemos relaciones con la ideologia del ser saludable, enfatizando el ideal de robustez y el ideal de delgadez y identificamos que la Educación Física contribui con la associación entre salud y un padrón específico de estética corporal por medio de mediciones antropometricas, seya por el coeficiente de robustez, pelo método para identificar el somatotipo ou pelo índice de masa corporal.

Palabras clave: Educación Física. Salud. Estética.

\title{
REFERÊNCIAS
}

ANZAI, Koiti. O corpo enquanto objeto de consumo. Revista Brasileira de Ciências do Esporte, Vitória, v. 21, n. 2-3, p.71-76, jan./maio, 2000.

AZEVEDO, Fernado. Da educação física: o que ela é, o que tem sido, o que deveria ser. São Paulo: Melhoramentos, 1960.

Da educação physica. São Paulo: Weiszflog Irmãos, 1920

Movimento, Porto Alegre, v. 15, n. 04, p. 175-191, outubro/dezembro de 2009. 
BANKOFF, A. D. P.; MOUTINHO, E. A. Obesidade infantil e avaliação em pré-escolares. Revista Brasileira de Ciências do Esporte, Campinas, v. 23, n. 3, p.105-120, maio, 2002.

BARAFILHO, M. G.; BIESEK, S.; FERNANDES, A. P.T.;ARAÚJO, C. G. S. de. Comparação do padrão de atividade física e peso corporal pregressos e atuais entre graduados e mestres em educação física. Revista Brasileira de Ciências do Esporte, Florianópolis, v. 21, n. 2-3, p.30-35, jan./maio, 2000.

BIESEK, S.; CÔRTE, S.; MOREIRA, S. B. Efeitos de 15 dias de suplementação de aminoácidos de cadeia ramificada (ACR) na composição corporal e na resistência muscular estática durante uma expedição na Cordillera Blanca (Peru). Revista Brasileira de Ciências do Esporte, Florianópolis, v. 21, n. 2-3, p.30-35, jan./maio, 2000.

BRACHT, V. Um pouco de história para fazer história: 20 anos de CBCE. Revista Brasileira de Ciências do Esporte. Florianópolis, p.12-18, set., 1998. Número especial.

CARVALHO, Y. M. O mito da atividade física e saúde. SP: Hucitec, 1995.

DELLA FONTE, Sandra Soares; LOUREIRO, Róbson. A ideologia da saúde e a Educação Física. Revista Brasileira de Ciências do Esporte, Florianópolis, v. 18, n. 2, p.126-132, jan., 1997.

DINOÁ, M. A.; ASSIS, M. J. M. Avaliação pondero estrutural em alunos da escola estadual Ademar Veloso da Silveira em Campina Grande/PB. Revista Brasileira de Ciências do Esporte, Campinas, v. 11, n. 3, p.174-178, 1990.

DUARTE, M. F. S.; PETROSKI, E. L. Aptidão em remadores brasileiros. Revista Brasileira de Ciências do Esporte, São Paulo, v. 4, n. 2, p.30-39, jan., 1983.

FONSECA, Márcio A. Entre a vida governada e o governo de si. In: ALBUQUERQUE JÚNIOR; Durval M.; VEIGA-NETO, Alfredo; SOUZA FILHO, Alípio (Org.). Cartografias de Foucault. Belo Horizonte: Autêntica, 2008. Coleção Estudos Foucaultianos.

FOUCAULT, M. O nascimento da clínica. Tradução de Roberto Machado. 5. ed. Rio de Janeiro: Forense Universitária, 2001.

Resumo dos cursos do Collège de France (1970-1982). Tradução Andréa Daher. Rio de Janeiro: Jorge Zahar, 1997.

. História da sexualidade 1: a vontade de saber. Tradução Maria Thereza da Costa Albuquerque e J. A. Guilhon Albuquerque. Rio de Janeiro: Graal, 1988.

FRAGA, Alex. B. Exercício da informação: governo dos corpos no mercado da vida ativa. São Paulo: Autores Associados, 2006.

GÓIS JUNIOR, Edivaldo; LOVISOLO, Hugo R. Descontinuidades e continuidades do movimento higienista no Brasil do século XX. Revista Brasileira de Ciências do Esporte, Campinas, v. 25, n. 1, p.41-54, set., 2003.

Movimento, Porto Alegre, v. 15, n. 04, p. 175-191, outubro/dezembro de 2009. 
190 Artigos Orifinais Maria Isabel Brandão de Souza Mendes

GONÇALVES, Aguinaldo. A contribuição da epidemiologia da atividade física para a área da educação física/ciências do esporte. Revista Brasileira de Ciências do Esporte, Florianópolis, v. 17, n. 2, p.161-166, jan., 1996.

GONÇALVES, Aguinaldo; ARAUJO JR, Braulio; GHIROTTO, Flavia Maria Serra; MATIELO JR, Edgard; FATTARELLI, Ismael Fernando; AIRES, Suzana Gyco. Lesões desportivas: conceitos básicos. Revista Brasileira de Ciências do Esporte, Rio Grande do Sul, v. 16, n. 3, p.183-190, maio, 1995.

GUEDES, D. P. Estudo da correlação entre os somatotipos e variáveis de performance física em escolares. Revista Brasileira de Ciências do Esporte, Volta Redonda, v. 3, n. 3, p.99-105, maio, 1982.

GUEDES, D. P.; GRONDIM, L. M. V. Percepção de hábitos saudáveis por adolescentes: associação com indicadores alimentares, prática de atividade física e controle de peso corporal. Revista Brasileira de Ciências do Esporte, Campinas, v. 24, n. 1, p.23-45, set., 2002.

HEGG, R.; AMADIO, A. C.; STARK, R.E.; MANSOLDO, A.C.; KIDO, K.; TEIXEIRA, L. G. P.; BARROS, S. A.; BASTOS, F. Da C. Estudos antropométricos: campeonato juvenil de atletismo - São Paulo 1978. Revista Brasileira de Ciências do Esporte, Volta Redonda, v. 3, n. 2, p.63-79, jan., 1982.

KEHL, R. Povo são e povo doente: algumas considerações e dados anthropometricos. Brazil-Médico, Rio de Janeiro, p.280-283, 1920.

1925.

A fada hygia: primeiro livro de hygiene. Rio de Janeiro: Francisco Alves, 1936.

Cartilha de Higiene: alfabeto da saúde. Rio de Janeiro: Francisco Alves,

LEITE, C. F.; NUNES, V. G. S. Alteração da composição corporal e de VO2 máx. em pessoas obesas submetidas a um programa de exercícios aeróbicos e resistidos. Revista Brasileira de Ciências do Esporte, Campinas, v. 24, n. 1, p.99-116, set., 2002.

MELO, Victor. A. "Esporte é saúde": desde quando? Revista Brasileira de Ciências do Esporte, Campinas, v. 22, n. 2, p.55-67, jan., 2001.

OLIVOTO, R. R. Composição corporal: estudo comparativo da mensuração de pregas cutâneas e bioimpedância. Revista Brasileira de Ciências do Esporte, Florianópolis, v. 21, n. 1, p.787-791, set., 1999.

PALMA, Alexandre. Educação física, corpo e saúde: uma reflexão sobre outros "modos de olhar". Revista Brasileira de Ciências do Esporte, Campinas, v. 22, n. 2, p.23-39, jan., 2001.

PETROSKI, L.; CARDOSO, A.; ALVES, M. O estudo somatotipológico dos atletas da modalidade de atletismo de Santa Catarina. Revista Brasileira de Ciências do Esporte, Volta Redonda, v. 3, n. 3, p.93-98, maio, 1982.

Movimento, Porto Alegre, v. 15, n. 04, p. 175-191, outubro/dezembro de 2009. 
PITANGA, F. J. G. Associações entre o nível de prática de atividade física e perfil lipídico em adultos de ambos os sexos. Revista Brasileira de Ciências do Esporte, Florianópolis, v. 21, n. 1, p.836-842, set., 1999.

QUINT, Fernanda. O.; MATIELLO JÚNIOR, Edgard. O gosto amargo do exercício como remédio nas pedagogias do medo e da culpa. Revista Brasileira de Ciências do Esporte, Florianópolis, v. 21, n. 1, p.867-872, set., 1999.

SILVA, Ana Márcia. Corpo e diversidade cultural. Revista Brasileira de Ciências do Esporte, Campinas, v. 23, n. 1, p.87-98, set., 2001.

SILVA, D. K.; PETROSKI, E. L. Percepção da forma corporal e aspectos morfológicos em adultos de meia idade. Revista Brasileira de Ciências do Esporte, Florianópolis, v. 21, n. 1, p.802-807, set., 1999.

SILVA, F. M.; MARTINS, C. M. L. Atividade física e controle do peso corporal: experiência de um spa urbano. Revista Brasileira de Ciências do Esporte, Florianópolis, v. 21, n. 1, p.831-836, set., 1999.

SILVA, R. C. R. Relação entre aptidão física e fatores de risco para a doença coronariana em adolescentes de Niterói, Rio de Janeiro. Revista Brasileira de Ciências do Esporte, Florianópolis, v. 21, n. 1, p.883-887, set., 1999.

SOARES, C. L. Educação física: raízes européias e Brasil. 2. ed. Campinas: Autores Associados, 2001.

SOARES, I. M.; SILAMI-GARCIA, E.; RODRIGUES, L. O. C.; LIMA, N. R. V.; CAMARA, A. M. C. S.; PEREIRA, S. M. Perfil de jogadoras de handebol de alto nível. Revista Brasileira de Ciências do Esporte, São Paulo, v. 5, n. 3, p.85-89, maio, 1984.

VAGO, T. M. Cultura escolar, cultivo de corpos: educação physica e gymnastica como práticas constitutivas dos corpos de crianças no ensino público primário de Belo Horizonte (1906-1920). Tese (Doutorado em Educação) - Universidade de São Paulo, São Paulo, 1999. 